\title{
Liquid low-level radioactive wastes treatment by using hydrophobized track-etched membranes
}

\author{
M.V. Zdorovets ${ }^{\mathrm{a}, \mathrm{b}, \mathrm{c}, *}$, A.B. Yeszhanov ${ }^{\mathrm{a}, \mathrm{b}}$, I.V. Korolkov ${ }^{\mathrm{a}, \mathrm{b}, * *}$, O. Güven ${ }^{\mathrm{e}}$, S.S. Dosmagambetova ${ }^{\mathrm{a}}$, \\ D.I. Shlimas $^{\mathrm{a}, \mathrm{b}}$, Zh.K. Zhatkanbayeva ${ }^{\mathrm{a}}$, I.S. Zhidkov ${ }^{\mathrm{c}}$, P.V. Kharkin ${ }^{\mathrm{b}}$, V.N. Gluchshenko ${ }^{\mathrm{b}}$, \\ D.A. Zheltov ${ }^{\mathrm{b}}$, N.A. Khlebnikov ${ }^{\text {c,d }}$, I.E. Kuklin ${ }^{\mathrm{c}}$ \\ ${ }^{a}$ L.N.Gumilyov Eurasian National University, Satpaev str., 5, 010008 Nur-Sultan, Kazakhstan \\ ${ }^{\mathrm{b}}$ The Institute of Nuclear Physics, 050032, Ibragimov str., 1, Almaty, Kazakhstan \\ ${ }^{\mathrm{c}}$ Ural Federal University, 620002, Mira str. 19, Ekaterinburg, Russia \\ ${ }^{\mathrm{d}}$ Institute of Solid State Chemistry, UB RAS, 620990, 91 Pervomaiskaya st., Ekaterinburg, Russia \\ ${ }^{\mathrm{e}}$ Department of Chemistry, Hacettepe University, 06800 Beytepe, Ankara, Turkey
}

\section{A R T I C L E I N F O}

\section{Keywords:}

Track-etched membranes

Hydrophobization

Membrane distillation

Styrene

Liquid radioactive waste treatment

\begin{abstract}
A B S T R A C T
In this paper, we present the results of liquid low-level radioactive wastes (LLLRW) treatment by direct contact membrane distillation (DCMD) using polyethylene terephthalate (PET) track-etched membranes (TeMs). PET TeMs were modified by styrene and triethoxyvinylsilane (TEVS) using UV-induced grafting. Modification led to increase in the contact angle to $99^{\circ}$ of PET TeMs (pore size from 150 to $300 \mathrm{~nm}$ ). Hydrophobic PET TeMs were investigated by X-ray photoelectron spectroscopy (XPS), Fourier-transform infrared spectroscopy (FTIR), goniometric analysis, gas permeability test, liquid entry presser (LEP) analysis and scanning electron microscope (SEM). Prepared membranes were tested in treatment of LLLRW by DCMD. The influence of pore size on water flux and rejection degree was studied. Rejection degree was evaluated by conductometry and atomic emission methods. Decontamination factors (evaluated by gamma-ray spectroscopy) for ${ }^{60} \mathrm{Co},{ }^{137} \mathrm{Cs}$, and ${ }^{241} \mathrm{Am}$ were found to be 85, 1900 and 5 respectively. In most cases degree of rejection of $\mathrm{Cs}, \mathrm{Mo}, \mathrm{Sr}, \mathrm{Sb}, \mathrm{Al}, \mathrm{Ca}, \mathrm{Fe}, \mathrm{K}, \mathrm{Mg}$ and $\mathrm{Na}$ ions were more than $90 \%$ and close to $100 \%$. The use of TeMs with a narrow pores size distribution and without tortuous channels allowed us to achieve better purification from radioactive wastes in comparison with hollow-fiber membranes.
\end{abstract}

\section{Introduction}

Development in nuclear power generation (Jia et al., 2018), tragedy of Fukushima Daiichi accident (Jia et al., 2017b), and the environmental problems of former nuclear test sites including those in Kazakhstan (Semipalatinsk nuclear test site) (Evseeva et al., 2012) led to the fact that treatment and concentration of liquid low-level radioactive wastes (LLLRW) have received increasing attention all over the world (Liu and Wang, 2013). Because of their large volumes and low levels of radioactive materials, LLLRW should be concentrated and then solidified with cement, glass, asphalt or bitumen (Zakrzewska-Trznadel, 2013). In recent years, membrane methods for separating liquid mixtures have been intensively developed with promising results to resolve a wide range of scientific and environmental problems. One such process is membrane distillation (MD), a method of separating and concentrating aqueous solutions of substances (González et al., 2017; Wang and Chung, 2015). The advantages of MD are low energy consumption, low operating temperature, and not requirement of overpressure. The main drawback of this process is the short lifetime of the membranes due to gradual surface fouling and poor performance (Tijing et al., 2014; Wang and Chung, 2015). Despite this, MD is widely used for the desalination of seawater and groundwater (Hubadillah et al., 2018; Ruiz-Aguirre et al., 2018; Zhao et al., 2017), wastewater and natural water treatment to remove heavy metals (Attia et al., 2017; Naidu et al., 2017; Quist-Jensen et al., 2017), radionuclides and pesticides (Jia et al., 2018, 2017a; 2017c).

The membranes used for the MD process should fulfill the following requirements: hydrophobicity, high porosity, water impermeability, chemical and mechanical stability, uniform pore size distribution (Alkhudhiri et al., 2012; El-Bourawi et al., 2006). Hydrophobicity of the

\footnotetext{
* Corresponding author. L.N.Gumilyov Eurasian National University, Satpaev str., 5, 010008 Nur-Sultan, Kazakhstan.

** Corresponding author. L.N.Gumilyov Eurasian National University, Satpaev str., 5, 010008 Nur-Sultan, Kazakhstan.

E-mail addresses: mzdorovets@inp.kz (M.V. Zdorovets), i.korolkov@inp.kz (I.V. Korolkov).
} 


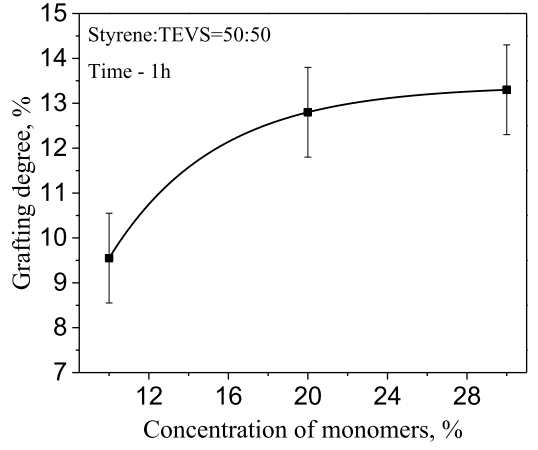

(a)

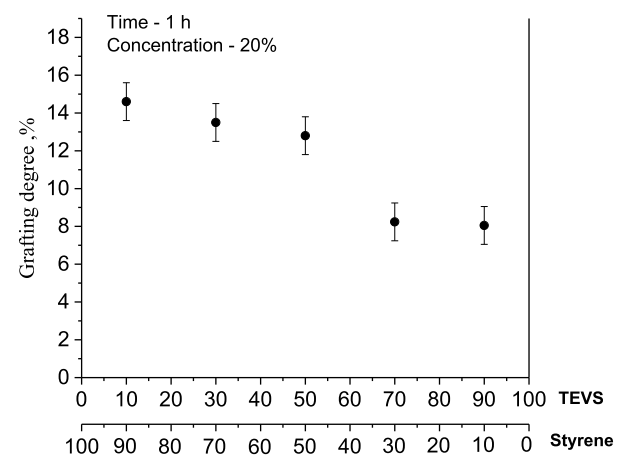

(b)

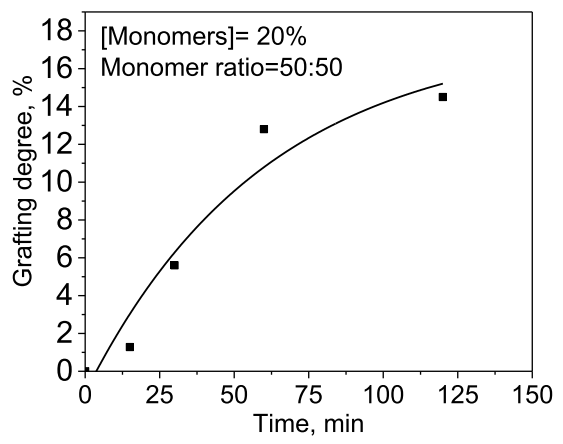

(c)

Fig. 1. The degree of simultaneous grafting of styrene and TEVS to the surface of PET TeMs with (a) various concentration, (b) monomer ratios and (c) time.

Table 1

Contact angle and pore sizes of PET TeMs obtained under various grafting conditions (total monomer concentration and monomer ratios at $1 \mathrm{~h}$ of grafting).

\begin{tabular}{|c|c|c|c|c|c|c|c|}
\hline № sample & Monomer ratio & $\begin{array}{l}\text { Concentration of monomer, } \\
\%\end{array}$ & Contact angle, & $\begin{array}{l}\text { Pore size (SEM } \\
\text { analysis), } \mathrm{nm}\end{array}$ & $\begin{array}{l}\text { Effective pore size, } \\
\mathrm{nm}\end{array}$ & $\begin{array}{l}\text { Liquid Entry Pressure } \\
\text { (LEP), MPa }\end{array}$ & $\begin{array}{l}\text { Grafting degree, } \\
\%\end{array}$ \\
\hline 1 & PET TeMs & - & 54 & $220 \pm 20$ & $208 \pm 6$ & - & - \\
\hline 2 & Styrene_TEVS (50:50) & 20 & 99 & $206 \pm 21$ & $200 \pm 6$ & 0.34 & 13 \\
\hline 3 & Styrene_TEVS (50:50) & 10 & 88 & $210 \pm 24$ & $203 \pm 7$ & 0.15 & 10 \\
\hline 4 & Styrene_TEVS (10:90) & 20 & 89 & $200 \pm 20$ & $195 \pm 7$ & 0.13 & 8 \\
\hline 5 & Styrene_TEVS (90:10) & 20 & 82 & $211 \pm 21$ & $203 \pm 7$ & 0.13 & 15 \\
\hline 6 & Styrene_TEVS (70:30) & 20 & 85 & $200 \pm 21$ & $193 \pm 7$ & 0.14 & 8 \\
\hline 7 & Styrene_TEVS (30:70) & 20 & 80 & $208 \pm 23$ & $200 \pm 7$ & 0.04 & 14 \\
\hline 8 & Styrene_TEVS $(50: 50)^{\mathrm{a}}$ & 20 & 87 & $287 \pm 25$ & $283 \pm 6$ & 0.13 & 14 \\
\hline 9 & Styrene_TEVS $(50: 50)^{\mathrm{b}}$ & 20 & 92 & $242 \pm 27$ & $235 \pm 6$ & 0.25 & 13 \\
\hline 10 & Styrene_TEVS $(50: 50)^{c}$ & 20 & 99 & $142 \pm 12$ & $131 \pm 6$ & 0.39 & 12 \\
\hline
\end{tabular}

a - PET TeMs with pore size of $300 \mathrm{~nm}$.

b - PET TeMs with pore size of $250 \mathrm{~nm}$.

c - PET TeMs with pore size of $150 \mathrm{~nm}$.

membrane surface prevents wetting and provides good separation characteristics. Wetting properties of membranes are usually evaluated by liquid entry pressure (LEP), which is defined as the pressure that must be applied before the fluid goes through a membrane. For stable operation, LEP values should not exceed 2.5 bar (Chew et al., 2017). The wetting contact angle allows estimating the hydrophobicity and hydrophilicity of membrane surface. A water contact angle above $90^{\circ}$ is required for the treatment of salty aqueous solutions with MD (An et al., 2017).

The polymers mostly used in manufacturing membranes for MD applications are poly(tetrafluoroethylene), polypropylene, and poly (vinylidenefluoride) due to their hydrophobic nature and thermal stability (An et al., 2016; Khayet, 2011; Shirazi et al., 2014). However, these types of membranes also have their drawbacks such as poor productivity, high cost, fouling of the hydrophobic surface, which leads to reduction in water purification (González et al., 2017; McGaughey et al., 2017). Thus, searching for new type membranes for MD is an important task.

Recently track-etched membranes (TeMs) were started to be use in the process of MD (Gancarz et al., 2015). Regular geometry of the pores with the ability to control their amount per unit area and excellent distribution of pore sizes together with low thickness and tortuosity make track-etched membranes (TeMs) attractive for application in precise separation methods (He and Guo, 2015; Korolkov et al., 2018b, 2017). The most frequently used ion-track membranes are based on poly(ethylene terephthalate) (PET) (Kurakhmedov et al., 2017; Apel et al., 2018; Filippova et al., 2016; Korolkov et al., 2019, 2018c; Wang et al., 2018). As mentioned above, for membrane distillation it is important that the membrane should possess hydrophobic properties. However PET TeMs has medium-hydrophobic properties, and for 


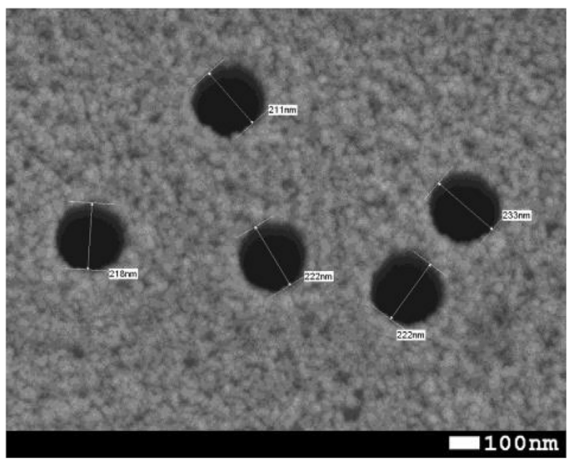

(a)

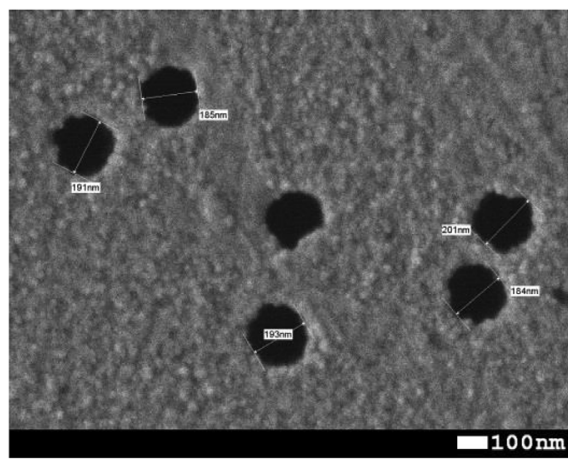

(c)

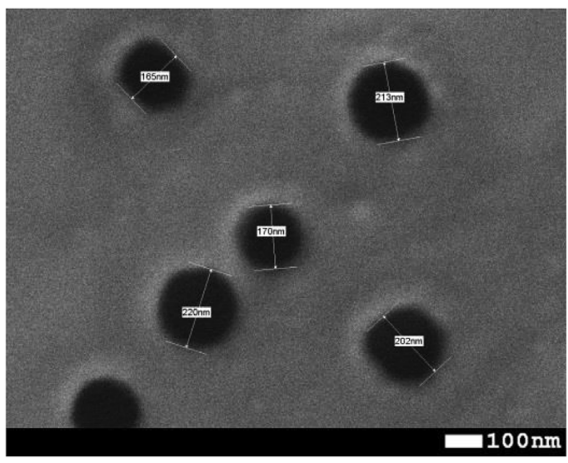

(e)

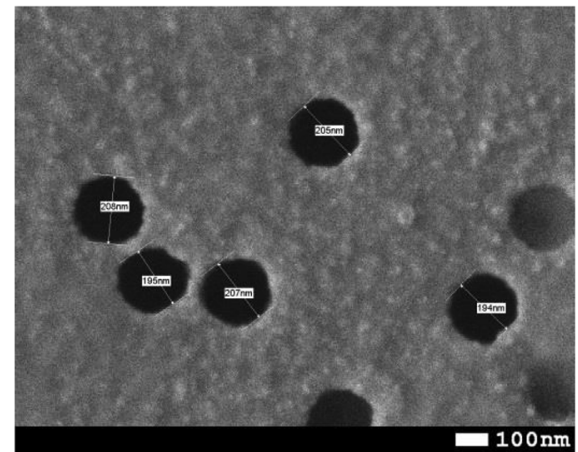

(b)

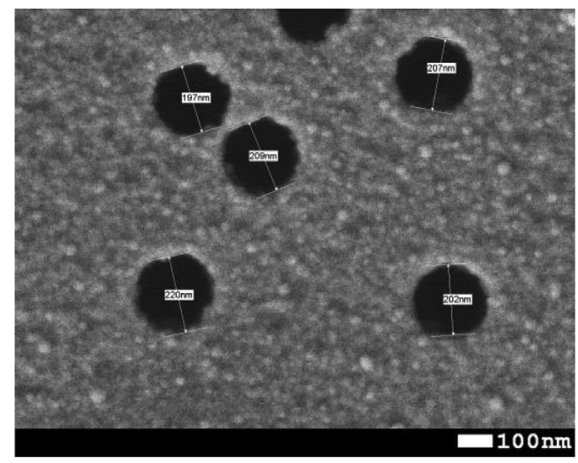

(d)

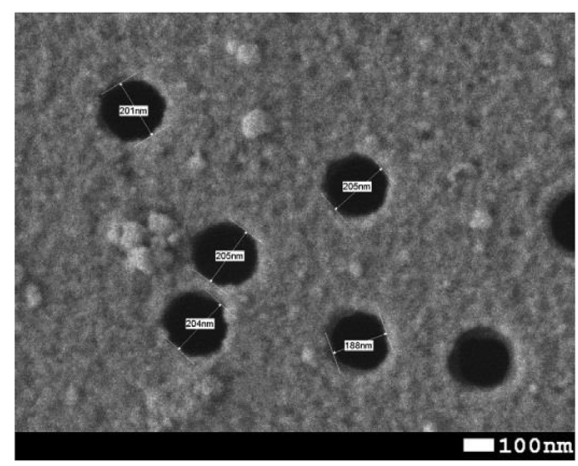

(f)

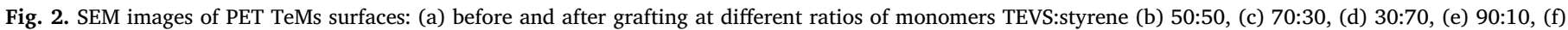
10:90.

successful application in MD process the membranes should have water-repellent properties. The most common method of hydrophobization is to cover the surface by hydrophobic layer. In our previous work, hydrophobic PET films were obtained by covalent bonding of silicon monomers such as dichlorodimethylsilane (Korolkov et al., 2018c) and UV-induced graft polymerization of styrene (Korolkov et al., 2019) TEVS in presents of acrylic acid and N-vinylimidazole (Korolkov et al., 2018a). In the last work, the hydrophilic nature of acrylic acid did not allow to obtain large contact angle of PET TeMs. Replacing these additives with styrene may result in a better outcome.

In this paper, we consider the method of UV-graft polymerization of the surface of PET by copolymerization of styrene and triethoxyvinylsilane (TEVS). For the first time, chemically modified TeMs with narrow pore size distribution and not tortuous channels will be tested in MD of LLLRW solutions. These properties of TeMs led to high salt and radioactive isotopes rejection degree.

\section{Experimental part}

\subsection{Chemicals}

Sodium hydroxide, N,N-dimethylformamide, benzophenone, sodium chloride, trichloromethane, TEVS, styrene were purchased from Sigma-Aldrich. Deionized water $(18.2 \mathrm{M} \Omega)$ obtained by water purification system Akvilon D-301 was used in all experiments. Purification of monomers from inhibitors was carried out by passing through a column filled with neutral alumina.

\subsection{Preparation of the membrane and their modification}

TeMs were prepared by irradiation $12 \mu \mathrm{m}$ thick PET films with ${ }^{84} \mathrm{Kr}^{15+}$ ions with an energy of $1.75 \mathrm{MeV} /$ nucleon and ion fluence of $1 \cdot 10^{8}$ ion $/ \mathrm{cm}^{2}$ using the DC-60 accelerator in Astana branch of Nuclear Physics Institute of Kazakhstan. Then membranes with certain pore diameters were obtained by means of photosensitization for $30 \mathrm{~min}$ 

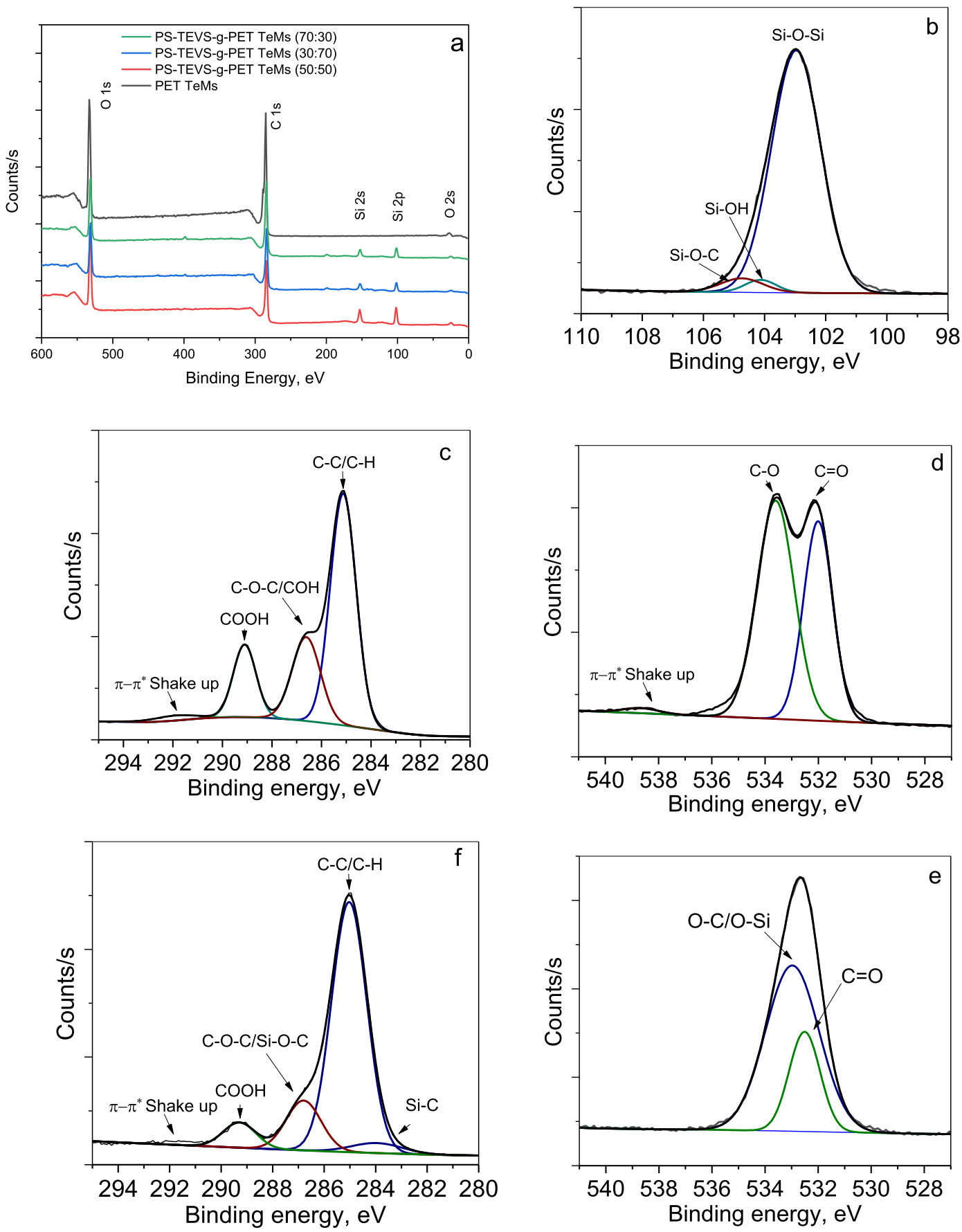

Fig. 3. XPS spectra (a) survey and high-resolution for (b) $\mathrm{Si}_{2 \mathrm{p}}$, (c,f) $\mathrm{C}_{1 \mathrm{~s}}$ and (d,e) O1s of (c,d) PET TeMs and (f,e) PET TeMs-g-PS-TEVS (50:50).

Table 2

XPS surface composition of the samples.

\begin{tabular}{|c|c|c|c|c|c|c|c|c|c|c|c|c|}
\hline \multirow[t]{2}{*}{ Sample } & \multicolumn{3}{|c|}{ Atomic concentration, \% } & \multicolumn{4}{|c|}{ High resolution $\mathrm{C}_{1 \mathrm{~s}}$ moieties, $\%$} & \multicolumn{2}{|c|}{$\mathrm{O}_{1 \mathrm{~s}}$ moieties, $\%$} & \multicolumn{3}{|c|}{$\mathrm{Si}_{2 \mathrm{p}}$ moieties, $\%$} \\
\hline & $\mathrm{C}$ & $\mathrm{O}$ & $\mathrm{Si}$ & $\mathrm{Si}-\mathrm{C}$ & $\mathrm{C}-\mathrm{C} / \mathrm{C}-\mathrm{H}$ & $-\mathrm{Si}-\mathrm{O}-\mathrm{C} / \mathrm{C}-\mathrm{O}-\mathrm{C}$ & $\mathrm{C}=\mathrm{O}$ & $\mathrm{C}-\mathrm{O}(\mathrm{Si}-\mathrm{O})$ & $\mathrm{C}=\mathrm{O}$ & $\mathrm{Si}-\mathrm{O}-\mathrm{C}$ & $\mathrm{Si}-\mathrm{OH}$ & $\mathrm{Si}-\mathrm{O}-\mathrm{Si}$ \\
\hline PET TeMs & 71.9 & 28.1 & - & - & 66.1 & 19.8 & 14.1 & 57.5 & 42.5 & - & - & - \\
\hline PET TeMs-g-PS-TEVS (50:50) & 66.7 & 22.1 & 11.2 & 4.3 & 77.6 & 14.2 & 3.9 & 74.2 & 25.8 & 4.6 & 3.0 & 92.4 \\
\hline PET TeMs-g-PS-TEVS (70:30) & 68.5 & 23.2 & 8.3 & 5.9 & 76.9 & 12.9 & 4.3 & 85.8 & 14.2 & 4.9 & 4.5 & 90.6 \\
\hline PET TeMs-g-PS-TEVS (30:70) & 68.4 & 22.5 & 9.1 & 8.5 & 74.1 & 12.9 & 4.5 & 87.5 & 12.5 & 4.8 & 5.1 & 90.1 \\
\hline PET TeMs-g-PS-TEVS (90:10) & 71.5 & 23.1 & 5.4 & 2.1 & 77.2 & 16.6 & 4.1 & 89.8 & 10.2 & 3.8 & 4.7 & 91.5 \\
\hline PET TeMs-g-PS-TEVS (10:90) & 67.5 & 22.3 & 10.2 & 9.1 & 74.2 & 12.5 & 4.2 & 80.8 & 19.2 & 6.8 & 5.9 & 87.3 \\
\hline
\end{tabular}




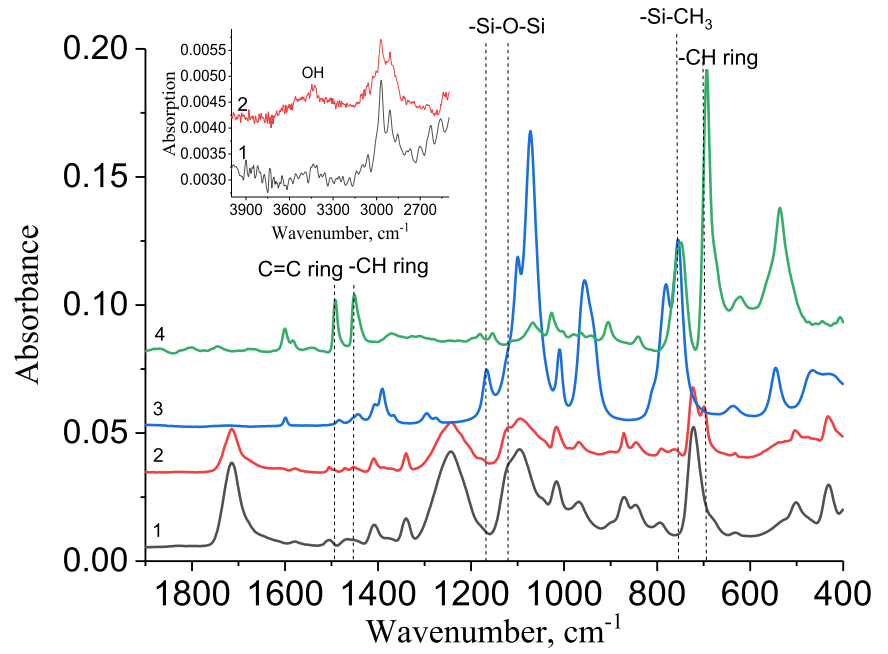

Fig. 4. FTIR-ATR spectra of 1-PET TeMs, 2 - PET TeMs-g-PS-TEVS (50:50), 3 clean TEVS, 4 - clean styrene.

from each side and chemical treatment in $2.2 \mathrm{M} \mathrm{NaOH}$ at $85^{\circ} \mathrm{C}$ for certain periods. Prepared membranes were dried and kept between paper sheets under ambient conditions before use.

PET TeMs was hydrophobized by UV-induced grafting of styrene and TEVS. PET films $(10 \times 15 \mathrm{~cm})$ were rinsed with water in an ultrasonic bath. Then samples were dried and immersed in 5\% benzophenone solution in N,N-dimethylformamide (DMF). The films removed from DMF solution were placed into chloroform solutions (containing $1.5-2 \%$ water) of monomers with $10-20 \%$ concentration with various monomer ratios. To remove dissolved oxygen form the solution, argon purging was carried out for $20 \mathrm{~min}$. The UV-irradiation was carried out for certain time under UV lamp OSRAM Ultra Vitalux E27. After irradiation, samples were washed first in chloroform, and then in hot water to remove residual monomers, ungrafted homopolymers, and dried and weighed to calculate the grafting degree.

\subsection{Membrane characterization}

Agilent Cary 600 Series FTIR Spectrometer with ATR accessory was used to record FTIR spectra to study different chemical groups appeared after modification with scan range of $400-4000 \mathrm{~cm}^{-1}$, and resolution $4.0 \mathrm{~cm}^{-1}$. Spectral analysis was conducted by using Agilent Resolution Pro. X-ray photoelectron spectra were recorded on a Thermo Scientific K-Alpha spectrometer in the Ural Center for Shared Use "Modern Nanotechnology" Yekaterinburg, Russia. The vacuum in the analysis chamber was maintained at $2 \cdot 10^{-6} \mathrm{~Pa}$ or lower. Scanning electron microscope JEOL JSM-7500F, and atomic force microscope Smart SPM1000 AIST-NT (with tip radius not exceeding $10 \mathrm{~nm}$ ) were used for determination of pore diameters and characterization of morphology after PET TeMs modification. The gas flow rate was measured at a pressure drop of $20 \mathrm{kPa}$. Gas permeability test was used to estimate effective pore sizes of the membranes (Mulder, 1996). Contact angle (CA) was measured from five different positions of the films using Digital Microscope with 1000x magnification using static drop method at room temperature. Liquid Entry Pressure (LEP) was determined by using deionized water flow measurements according to recommendations described in (Ahmed et al., 2017; García-Payo et al., 2000). A circular sample with the radius of $1.25 \mathrm{~cm}$ was clenched inside the sealed chamber, and a test was run with air at gradually increasing pressure.

\subsection{Direct contact membrane distillation process}

DCMD rig used for the tests is described and presented in our previous paper (Korolkov et al., 2018a). The permeate flux was measured by weighing. Saline solution of $7.5-30 \mathrm{~g} / \mathrm{L} \mathrm{NaCl}$ as well as LLLRW samples obtained from WWR-K nuclear research reactor (Almaty, Kazakhstan) were tested. The degree of salt rejection was calculated by the change in conductivity that was measured using Hanna Instruments HI2030-01. OPTIMA-8000 ICP-Optical Emission Spectroscopy (the spectral range is $165-900 \mathrm{~nm}$ with resolution of $<0.009 \mathrm{~nm}$ at $200 \mathrm{~nm}$ ) was used to estimate elemental concentration of solutions before and after MD. Gamma-ray spectroscopy Canberra GM1520 with semiconductor Ge detector and the energy range (25-3000) keV was used to estimate the activity of radioisotopes.

\section{Results and discussion}

\subsection{Hydrophobization and characterization of PET TeMs}

In order to impart hydrophobic properties to PET TeMs surface, UVinduced graft copolymerization of two monomers with hydrophobic nature, namely styrene and TEVS was performed. Chloroform was used as a solvent in UV-induced graft polymerization since it has good transparent properties in UV-vis region (cutoff at around $245 \mathrm{~nm}$, while BP has broad absorption at $250-300 \mathrm{~nm}$ and from 310 to $370 \mathrm{~nm}$ ), and chloroform well dissolves monomers. Effect of different parameters such as concentration of monomers (10-30\%), ratio of monomers $(50: 50 ; 10: 90 ; 90: 10 ; 30: 70 ; 70: 30)$ and grafting time was studied to investigate the grafting process (Fig. 1).

Styrene has a high tendency for polymerization compared to TEVS (Agudelo et al., 2011), thus, as it can be seen from Fig. 1b, an increase in the styrene concentration leads to an increase in the grafting degree, and an increase in the concentration of TEVS, on the contrary leads to a decrease in degree of grafting for a given monomer concentration and grafting time. Fig. 1a shows that increasing of the monomer mixture concentration from 10 to $20 \%$ leads to a significant increase in the

Table 3

Chemical composition of the LLLRW sample and the effluent after DCMD process.

\begin{tabular}{|c|c|c|c|c|c|}
\hline Element & $\begin{array}{l}\text { Concentration in } \\
\text { the feed, } \mu \mathrm{g} / 1\end{array}$ & $\begin{array}{l}\text { Concentration in the permeate } \\
\text { (PET TeMs-g-PS-TEVS, } \\
\mathrm{d}=242 \mathrm{~nm} \text { ), } \mu \mathrm{g} / \mathrm{l} \text {, (degree of } \\
\text { rejection, \%) }\end{array}$ & $\begin{array}{l}\text { Concentration in the permeate } \\
\text { (PET TeMs-g-PS-TEVS, } \\
\mathrm{d}=206 \mathrm{~nm} \text { ), } \mu \mathrm{g} / \mathrm{l} \text {, (degree of } \\
\text { rejection, \%) }\end{array}$ & $\begin{array}{l}\text { Concentration in the permeate } \\
\text { (PET TeMs-g-PS-TEVS, } \\
\mathrm{d}=142 \mathrm{~nm} \text { ), } \mu \mathrm{g} / \mathrm{l} \text {, (degree of } \\
\text { rejection, \%) }\end{array}$ & $\begin{array}{l}\text { Concentration in the permeate } \\
\text { (PTFE hollow fiber membrane d- } \\
220 \mathrm{~nm} \text { ), } \mu \mathrm{g} / \mathrm{l} \text {, (degree of } \\
\text { rejection, \%) }\end{array}$ \\
\hline $\operatorname{Cs}(\sigma= \pm 26 \%)$ & 304 & $7.13(97.7 \%)$ & $1.18(99.6 \%)$ & $0.34(99.9 \%)$ & $34.3(88.7 \%)$ \\
\hline Mo $(\sigma= \pm 15 \%)$ & 458 & $4.14(99.1 \%)$ & $<0.3(99.9 \%)$ & $<0.3(99.9 \%)$ & $76.0(83.4 \%)$ \\
\hline $\operatorname{Sr}(\sigma= \pm 15 \%)$ & 136 & $<0,5(99.6 \%)$ & $<0.5(99.6 \%)$ & $<0.5(99.6 \%)$ & $11.1(91.8 \%)$ \\
\hline $\mathrm{Sb}(\sigma= \pm 15 \%)$ & 46.3 & $0.68(98.5 \%)$ & $<0.3(99.4 \%)$ & $<0.3(99.4 \%)$ & $8.96(80.6 \%)$ \\
\hline $\mathrm{Al}(\sigma= \pm 16 \%)$ & 660 & $<12(98.1 \%)$ & $<3(99.5 \%)$ & $<3(99.5 \%)$ & $<30(95.4 \%)$ \\
\hline $\mathrm{Ca}(\sigma= \pm 16 \%)$ & 1780 & $96.1(94.6 \%)$ & $84.2(95.2 \%)$ & $18.6(99.0 \%)$ & $208(88.3 \%)$ \\
\hline $\mathrm{Fe}(\sigma= \pm 10 \%)$ & 383 & $<2.4(99.4 \%)$ & $<0.6(99.8 \%)$ & $<0.6(99.8 \%)$ & $<6(98.4 \%)$ \\
\hline $\mathrm{K}(\sigma= \pm 15 \%)$ & 249200 & $1523(99.4 \%)$ & $236(99.9 \%)$ & $54.6(99.9 \%)$ & $7476(97 \%)$ \\
\hline $\operatorname{Mg}(\sigma= \pm 15 \%)$ & 1046 & $<4(99.6 \%)$ & $2,36(99.8 \%)$ & $<1(99.9 \%)$ & < $10(99.0 \%)$ \\
\hline $\mathrm{Na}(\sigma= \pm 15 \%)$ & 4710000 & $103(99.9 \%)$ & $17.6(99.9 \%)$ & 1.87 (99.9\%) & $601(99.0 \%)$ \\
\hline
\end{tabular}



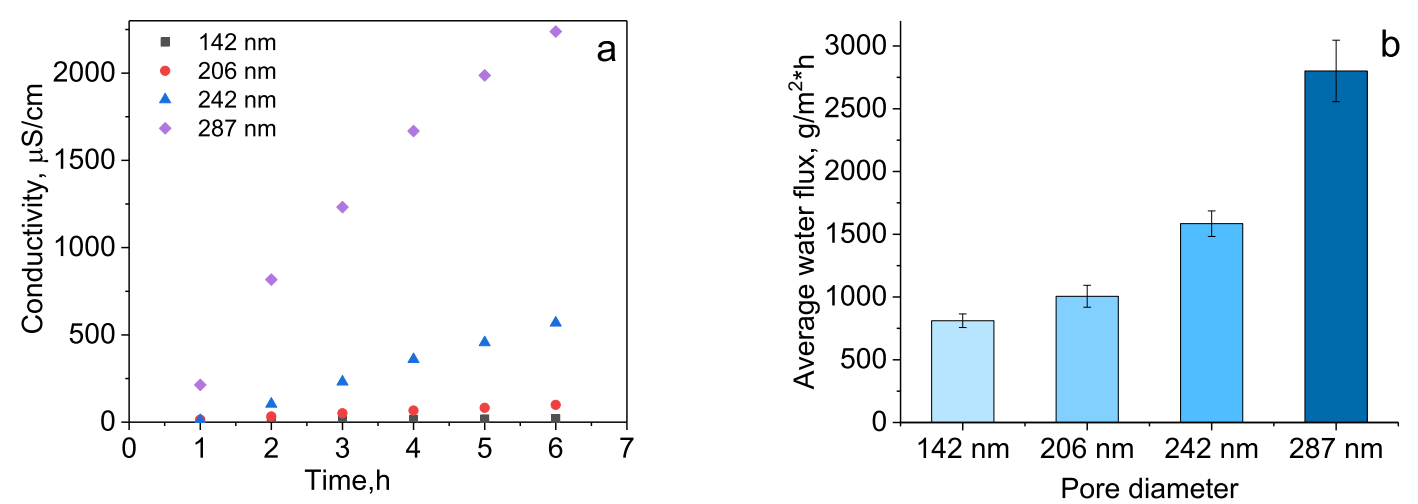

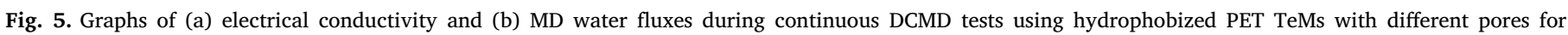
radioactive waste solution.

grafting degree, whereas further increase in concentration leads only to a slight increase in the grafting degree. Thus, increasing concentration of monomers above $20 \%$ is not effective. Fig. 1c shows relationship of grafting degree with time at constant concentration of monomer $20 \%$ and monomer ratio 50:50. Grafting degree reaches $12.8 \%$ after $60 \mathrm{~min}$ and $14.5 \%$ after $120 \mathrm{~min}$ of grafting. An increase in the time of grafting from 60 to $120 \mathrm{~min}$ lead to an insignificant increase in the degree of grafting, thus, the optimum time for grafting is considered as $1 \mathrm{~h}$. To evaluate the hydrophobic properties of prepared samples, the method of contact angle measurement was used (Table 1). As it can be seen from Table 1, contact angle is dependent on the degree of grafting and on the concentration of monomer and their ratio.

Along with that, the pore diameter of the membranes also significantly affects contact angle and LEP. With an increase in the pore diameter from 142 to $287 \mathrm{~nm}$, the value of the capillary effect exceeds the surface tension force of a water droplet. It is also confirmed a decrease in LEP with an increase in pore diameter. However, according to the recommendation, the LEP preferentially should be $>2.5$ bar for a successful application in MD. The use of a membrane with a pore diameter of $287 \mathrm{~nm}$ may lead to liquid slipping. Thus, according to the above given results, the optimal conditions for the modification of PET TeMs with pore sizes $150-250 \mathrm{~nm}$ by UV-induced graft polymerization of styrene and TEVS leading to maximum hydrophobization of membranes with $99^{\circ}$ of water contact angle and preserving the pore structure are as follows, grafting time $60 \mathrm{~min}$, total monomer concentration $20 \%$ and monomer ratio of 50:50.

Analysis of previously published papers on using styrene and TEVS as hydrophobic agent shows us that contact angle of different materials can be increased up to $94-104^{\circ}$ (Arkles, 2015; Guo et al., 2016) and in some cases to $161^{\circ}$ (on tunable nanostructures polystyrene) (Xu et al., 2007) and $156^{\circ}$ (Wang et al., 2019).

SEM analysis was used to determine pore sizes and investigate morphology after modification of the membranes. Electron microphotographs of the PET TeMs surfaces after grafting at different monomer ratios are shown in Fig. 2, the change in pore diameters is summarized in Table 1 . The analysis shows a slight narrowing of the pore diameter with the degree of grafting. Thus, graft polymerization is carried out with preservation of the pore structure of the membranes.

As can be seen from Table 1, the membranes with higher degree of grafting do not show the maximum contact angle, this is probably also due to the different chemical composition of the surface at different ratios of monomers. FTIR and XPS analysis were used to study chemical content of the membranes. XPS analysis shows changes in chemical composition of very top layer $(\sim 10 \mathrm{~nm})$ of the membranes before and after graft copolymerization of styrene and TEVS (at constant monomer concentration $20 \%$, pore diameter $200 \mathrm{~nm}$ ). Survey spectrum of pristine membrane (Fig. 3a) consists of oxygen and carbon, whereas grafting of styrene and TEVS led to emerging of new peaks corresponding to Si. Moreover low intensity peaks at around $199 \mathrm{eV}$ and $398 \mathrm{eV}$ corresponding to $\mathrm{Cl}$ and $\mathrm{N}$ respectively were detected, that most likely to obtain from contamination. Top surface elemental composition determined by XPS is summarized in Table 2. Graft copolymerization of styrene and TEVS led to decreasing content of $\mathrm{C}$ and $\mathrm{O}$ and increasing silicon up to $11.2 \%$. High-resolution $\mathrm{Si}_{2 \mathrm{p}}$ spectra (Fig. $3 \mathrm{~b}$ ) consist of 3 peaks at $102.9 \mathrm{eV}(\mathrm{Si}-\mathrm{O}-\mathrm{Si})$ with high intensity, at $104.1 \mathrm{eV}(\mathrm{Si}-\mathrm{O}-\mathrm{H})$ and $104.7 \mathrm{eV}$ (Si-O-C) with low intensities, which is characteristic for silane compounds (Khung et al., 2015). A quantitative analysis of the ratio of these peaks shows that the surface at about $90-92 \%$ consists of $\mathrm{Si}-\mathrm{O}-\mathrm{Si}$ linkages, and only at $8-10 \%$ consists of $\mathrm{Si}-\mathrm{O}-\mathrm{C}$ and $\mathrm{Si}-\mathrm{OH}$ linkages. High-resolution $\mathrm{C} 1 \mathrm{~s}$ spectra were recorded after grafting of styrene and TEVS at different monomer ratios (data are presented in Table 2 and spectra are shown in Fig. 3c,f). The C1s peaks of pristine PET TeMs are attributed to $\mathrm{C}-\mathrm{C} / \mathrm{C}-\mathrm{H}$ at $284.7 \mathrm{eV}, \mathrm{C}-\mathrm{O} / \mathrm{C}-\mathrm{OH}$ at $286.4 \mathrm{eV}$, and $\mathrm{C}=\mathrm{O}$ at $288.8 \mathrm{eV}$, however graft copolymerization led to appearance Si-C linkage at around $282.9 \mathrm{eV}$ with low intensity and peak at $286.4 \mathrm{eV}$ is attributed not only to $\mathrm{C}-\mathrm{O} / \mathrm{C}-\mathrm{OH}$, but also to Si-O-C linkage. The authors (Khung et al., 2015) also found similar observations during hydrosilylation carried out on bifunctional molecules by using thermal treatment and photochemical treatment. Highresolution O1s spectra (Fig. $3 \mathrm{~d}, \mathrm{e}$ ) also helped to explain surface content of PET TeMs before and after grafting. The O1s peaks of initial PET membrane are attributed to $\mathrm{C}-\mathrm{O}(531.7 \mathrm{eV})$ and $\mathrm{C}=\mathrm{O}(533.2 \mathrm{eV})$. Moreover, $\pi-\pi^{*}$ shake up satellite peaks were observed at $538.7 \mathrm{eV}$. Graft polymerization of styrene and TEVS led to formation of $\mathrm{O}-\mathrm{Si} / \mathrm{C}-\mathrm{O}$ peak at $532.4 \mathrm{eV}$, and $\mathrm{C}=\mathrm{O}$ peak of PET appeared at $533.8 \mathrm{eV}$. From XPS spectra, it can be concluded that $\mathrm{Si}-\mathrm{OC}_{2} \mathrm{H}_{5}$ group react with formation of Si-O-Si links and a small amount of $\mathrm{Si}-\mathrm{OH}$ groups. Table 2 shows that with a monomer ratio styrene:TEVS $=50: 50$, minimum content of $\mathrm{Si}-\mathrm{OH}$ groups and oxygen was observed. It can explain the highest contact angle of the PET TeMs hydrophobized at these conditions.

To confirm graft polymerization and detect the presence of chemical group vibrations coming from TEVS and PS in modified PET TeMs, FTIR-ATR analysis was performed. FTIR-ATR spectra of original and grafted PET TeMs are shown in Fig. 4. Typical FTIR-ATR spectrum of unmodified PET TeMs consist of main absorption peaks at $2972 \mathrm{~cm}^{-1}$ (aromatic C-H), $2910 \mathrm{~cm}^{-1}$ (aliphatic C-H), $1715 \mathrm{~cm}^{-1}(\mathrm{C}=\mathrm{O})$, $1471 \mathrm{~cm}^{-1}\left(\mathrm{CH}_{2}\right.$ bending), $1410 \mathrm{~cm}^{-1}$ (ring $\mathrm{CH}$ in plane bending), $1341 \mathrm{~cm}^{-1} \quad\left(\mathrm{CH}_{2}\right.$ wagging), $1238 \mathrm{~cm}^{-1} \quad(\mathrm{C}(=\mathrm{O})-\mathrm{O}$ stretching), $1018 \mathrm{~cm}^{-1}$ (ring CCC bending), $970 \mathrm{~cm}^{-1}$ (O- $\mathrm{CH}_{2}$ stretching), $847 \mathrm{~cm}^{-1}$ (ring CC stretching). The presence of grafted TEVS is confirmed by $\mathrm{Si}-\mathrm{O}-\mathrm{Si}$ and $\mathrm{Si}-\mathrm{C}$ vibrations at $1180-1110,761 \mathrm{~cm}^{-1}$, respectively. Moreover, peak at $3300-3600 \mathrm{~cm}^{-1}$ was detected with low intensity that is corresponding to $\mathrm{OH}$. OH-groups can come from hydrolysis of $\mathrm{Si}_{-}-\mathrm{OC}_{2} \mathrm{H}_{5}$ groups. The results of FTIR spectroscopy correlate with XPS analysis.

In order to study the stability of the hydrophobic surface, the membranes were kept in water at room temperature and $85^{\circ} \mathrm{C}$ for $1 \mathrm{~h}$ to 
$48 \mathrm{~h}$. However, no changes were recorded in both the contact angle and the FTIR-ATR spectrum. This indicates the stability of the prepared hydrophobic layer of PET TeMs.

\subsection{Membrane distillation of liquid low-level radioactive wastes}

Membrane distillation of LLLRW with hydrophobic PET TeMs prepared at optimal conditions (20\% styrene, TEVS/St $=50: 50$ in chloroform, $60 \mathrm{~min}$ UV-irradiation) with different pore sizes of 142, 206, 242 and $287 \mathrm{~nm}$, was performed in direct contact mode with temperature control. LLLRW was purchased from Nuclear Research Reactor WWR-K (Almaty, Kazakhstan). LLLRW consist of different ions such as $\mathrm{Na}, \mathrm{Mg}, \mathrm{K}, \mathrm{Fe}, \mathrm{Ca}, \mathrm{Al}, \mathrm{Sb}, \mathrm{Sr}$, Mo, Cs measured by atomic emission method (Table 3 ) and consist of radioisotopes ${ }^{60} \mathrm{Co},{ }^{137} \mathrm{Cs}$ and ${ }^{241} \mathrm{Am}$ with different activities measured using Gamma Ray Spectrometer.

In DCMD experiment, hydrophobic PET TeMs with different pores were used to evaluate water fluxes and decontamination factor (D) since the efficiency of DCMD depends on pore diameter. Decontamination factor (D) was calculated according to (Korolkov et al., 2018a) the equation:

$D=\frac{a_{f}}{a_{p}}$

where $a_{f}$ and $a_{p}$ are specific activities of the feed and the permeate respectively.

Removal efficiency of wastes was primarily evaluated by electrical conductivity, which can be also used for overall efficiency of DCMD for metal ions rejections since the main components of the waste sample are $\mathrm{Na}$ and $\mathrm{K}$ which are highly effective to cause changes in conductivity.

DCMD results are presented in Fig. 5a. Membranes with pore diameters of 142, 206 and $242 \mathrm{~nm}$ showed minor changes in conductivity during MD, whereas using membranes with a pore diameter of $287 \mathrm{~nm}$ leads to a significant increase in conductivity from 214 to $2238 \mu \mathrm{S} / \mathrm{cm}$. Degrees of salt rejection for the hydrophobized PET TeMs with pore diameters of 142, 206 and $242 \mathrm{~nm}$ are $99.2 \%, 96.8 \%$ and $86.9 \%$ respectively. Fig. 5b shows us increasing average water fluxes from $810 \mathrm{~g} / \mathrm{m}^{2} \mathrm{~h}$ for the membrane with $142 \mathrm{~nm}$ pore diameter to $1584 \mathrm{~g} /$ $\mathrm{m}^{2} \mathrm{~h}$ for the membrane with $242 \mathrm{~nm}$ pore diameter. It should be noted that according to conductivity results (degree of salt rejection is around $5 \%$ ), high flux of membranes with pore sizes of $287 \mathrm{~nm}$ is due to wetting the channels.

According to Table 3, all degrees of rejection were more than $94 \%$, and most of them close to $100 \%$. For comparison, commercially available PTFE hollow fiber membrane with pore diameter of $220 \mathrm{~nm}$ was used under the same test conditions. Variations in ion concentration are caused by different salt concentration in feed solution. Decrease in the degree of salt rejection with an increase in the pore radius is associated with a decrease in the LEP (as it seen in Table 1). The higher the LEP, the lower the probability of liquid passing through the pores of the membranes.

Results on decontamination factors of radioisotopes are presented in Table 4. PET-g-PS-TEVS with pore diameters of 142 and $242 \mathrm{~nm}$ showed decontamination factor for ${ }^{60} \mathrm{Co}$ of $>85.4$, for ${ }^{137} \mathrm{Cs}$ of $>1900$ and 42 , for ${ }^{241} \mathrm{Am}$ of 5 and $>7$ respectively. It should be noted that in most cases data received was below detection limit. The decrease in the decontamination factor with an increase in the pore diameter is associated with a decrease in the LEP and the contact angle.

Decontamination factor for ${ }^{60} \mathrm{Co}$ is 10 , for ${ }^{137} \mathrm{Cs}$ is 439 and for ${ }^{241} \mathrm{Am}>2$ using standard PTFE membrane. Thus, the use of TeMs with a narrow pores size distribution allows us to achieve better purification of LLLRW from radioactive wastes. 


\section{Conclusions}

This study consider simple and effective method of hydrophobization of PET track-etched membranes by grafting of styrene and TEVS (at optimal conditions of $20 \%$ monomer concentration at monomer ratio $50: 50,60 \mathrm{~min}$ of photo-grafting) and their application for effective treatment of liquid low-level radioactive wastes. Prepared membranes were characterized by methods of XPS, FTIR before and after grafting as well as after membrane distillation process, SEM, gas permeability test to study pore structure and LEP and goniometric analysis to evaluate hydrophobic properties of the membranes. DCMD was controlled by gravimetric and conductometric analysis. The effect of membrane pore diameter on water flux and rejection degree was studied. Elemental composition of waste solutions was studied by gamma-ray spectroscopy and atomic emission method. Excellent degree of salt rejection of main elements of LLLRW such as $\mathrm{Cs}, \mathrm{Mo}, \mathrm{Sr}, \mathrm{Sb}, \mathrm{Al}, \mathrm{Ca}, \mathrm{Fe}, \mathrm{K}, \mathrm{Mg}$ and $\mathrm{Na}$ has been achieved and decontamination factor for ${ }^{60} \mathrm{Co},{ }^{137} \mathrm{Cs}$, and ${ }^{241} \mathrm{Am}$ were $>85,>1900$ and 5 respectively when using modified membrane with average pore diameters of $142 \mathrm{~nm}$ (average water flux for this membrane is $810 \mathrm{~g} / \mathrm{m}^{2} \mathrm{~h}$ ). Membranes with higher pore diameters of 206, 242 and 287 have fluxes of 1005,1584 and $2800 \mathrm{~g} / \mathrm{m}^{2} \mathrm{~h}$, however degree of salt rejection and decontamination factor are not sufficient due to the fact that modified membranes with large pore diameters have lower LEP and contact angle The optimum ratio between water flux and efficiency of salt rejection is achieved using $142 \mathrm{~nm}$ pore radius membranes. For the first time track-etched membranes were studied in membrane distillation of liquid low-level radioactive wastes. The use of track-etched membranes with a narrow pores size distribution and not tortuous channels allows us to achieve better purification from radioactive wastes in comparison with hollow-fiber membranes.

\section{Acknowledgement}

This study was funded by the Ministry of Education and Science of the Republic of Kazakhstan (grant No AP05132110 "Preparation of track-etched membranes with specified properties for membrane distillation and forward osmosis").

\section{References}

Agudelo, N.A., Perez, L.D., Lopez, B.L., 2011. A novel method for the synthesis of poly styrene-graft-silica particles using random copolymers based on styrene and triethoxyvinylsilane. Appl. Surf. Sci. 257, 8581-8586. https://doi.org/10.1016/j.apsusc. 2011.05.021.

Ahmed, F.E., Lalia, B.S., Hashaikeh, R., 2017. Membrane-based detection of wetting phenomenon in direct contact membrane distillation. J. Membr. Sci. 535, 89-93. https://doi.org/10.1016/j.memsci.2017.04.035.

Alkhudhiri, A., Darwish, N., Hilal, N., 2012. Membrane distillation: a comprehensive review. Desalination 287, 2-18. https://doi.org/10.1016/J.DESAL.2011.08.027.

An, A.K., Guo, J., Jeong, S., Lee, E.-J., Tabatabai, S.A.A., Leiknes, T., 2016. High flux and antifouling properties of negatively charged membrane for dyeing wastewater treatment by membrane distillation. Water Res. 103, 362-371. https://doi.org/10. 1016/J.WATRES.2016.07.060.

An, A.K., Guo, J., Lee, E.-J., Jeong, S., Zhao, Y., Wang, Z., Leiknes, T., 2017. PDMS/PVDF hybrid electrospun membrane with superhydrophobic property and drop impact dynamics for dyeing wastewater treatment using membrane distillation. J. Membr. Sci. 525, 57-67. https://doi.org/10.1016/j.memsci.2016.10.028.

Apel, P.Y., Blonskaya, I.V., Lizunov, N.E., Olejniczak, K., Orelovitch, O.L., ToimilMolares, M.E., Trautmann, C., 2018. Osmotic effects in track-etched nanopores. Small 14, 1703327. https://doi.org/10.1002/smll.201703327.

Arkles, B., 2015. Hydrophobicity, Hydrophilicity and Silane Surface Modification. Gelest, Inchttps://doi.org/10.1017/СВ09781107415324.004.

Attia, H., Alexander, S., Wright, C.J., Hilal, N., 2017. Superhydrophobic electrospun membrane for heavy metals removal by air gap membrane distillation (AGMD). Desalination 420, 318-329. https://doi.org/10.1016/J.DESAL.2017.07.022.

Chew, N.G.P., Zhao, S., Loh, C.H., Permogorov, N., Wang, R., 2017. Surfactant effects on water recovery from produced water via direct-contact membrane distillation. J. Membr. Sci. 528, 126-134. https://doi.org/10.1016/J.MEMSCI.2017.01.024.

El-Bourawi, M.S., Ding, Z., Ma, R., Khayet, M., 2006. A framework for better understanding membrane distillation separation process. J. Membr. Sci. 285, 4-29. https:// doi.org/10.1016/j.memsci.2006.08.002.

Evseeva, T., Belykh, E., Geras'kin, S., Majstrenko, T., 2012. Estimation of radioactive contamination of soils from the "Balapan" and the "Experimental field" technical areas of the Semipalatinsk nuclear test site. J. Environ. Radioact. 109, 52-59. https:// doi.org/10.1016/j.jenvrad.2012.01.002.

Filippova, E.O., Filippov, A.V., Shulepov, I.A., 2016. Experimental study of sliding friction for PET track membranes. IOP Conf. Ser. Mater. Sci. Eng. 125, 012020. https://doi. org/10.1088/1757-899X/125/1/012020.

Gancarz, I., Bryjak, M., Kujawski, J., Wolska, J., Kujawa, J., Kujawski, W., 2015. Plasma deposited fluorinated films on porous membranes. Mater. Chem. Phys. 151, 233-242. https://doi.org/10.1016/j.matchemphys.2014.11.059.

García-Payo, M.C., Izquierdo-Gil, M.A., Fernández-Pineda, C., 2000. Wetting study of hydrophobic membranes via liquid entry pressure measurements with aqueous alcohol solutions. J. Colloid Interface Sci. 230, 420-431. https://doi.org/10.1006/jcis. 2000.7106.

González, D., Amigo, J., Suárez, F., 2017. Membrane distillation: perspectives for sustainable and improved desalination. Renew. Sustain. Energy Rev. 80, 238-259. https://doi.org/10.1016/j.rser.2017.05.078.

Guo, Y.B., Yang, L., Wang, D.G., 2016. Preparation and hydrophobic behaviours of polystyrene composite coating. Surf. Eng. 32, 95-101. https://doi.org/10.1179/ 1743294415Y.0000000016.

He, Z.-B., Guo, S.-L., 2015. Applications of nuclear track membranes to filtration of medical injections and various transfusions to remove solid particles. Phys. Procedia 80, 131-134. https://doi.org/10.1016/j.phpro.2015.11.081.

Hubadillah, S.K., Othman, M.H.D., Matsuura, T., Rahman, M.A., Jaafar, J., Ismail, A.F., Amin, S.Z.M., 2018. Green silica-based ceramic hollow fiber membrane for seawate desalination via direct contact membrane distillation. Separ. Purif. Technol. 205, 22-31. https://doi.org/10.1016/J.SEPPUR.2018.04.089.

Jia, F., Li, J., Wang, J., 2017a. Recovery of boric acid from the simulated radioactive wastewater by vacuum membrane distillation crystallization. Ann. Nucl. Energy 110, 1148-1155. https://doi.org/10.1016/J.ANUCENE.2017.07.024.

Jia, F., Li, J., Wang, J., Sun, Y., 2017b. Removal of strontium ions from simulated radioactive wastewater by vacuum membrane distillation. Ann. Nucl. Energy 103 363-368. https://doi.org/10.1016/J.ANUCENE.2017.02.003.

Jia, F., Li, J., Wang, J., Sun, Y., 2017c. Removal of strontium ions from simulated radioactive wastewater by vacuum membrane distillation. Ann. Nucl. Energy 103 363-368. https://doi.org/10.1016/j.anucene.2017.02.003.

Jia, F., Yin, Y., Wang, J., 2018. Removal of cobalt ions from simulated radioactive wastewater by vacuum membrane distillation. Prog. Nucl. Energy 103, 20-27. https:// doi.org/10.1016/J.PNUCENE.2017.11.008.

Khayet, M., 2011. Membranes and theoretical modeling of membrane distillation: a review. Adv. Colloid Interface Sci. 164, 56-88. https://doi.org/10.1016/j.cis.2010.09. 005 .

Khung, Y.L., Ngalim, S.H., Scaccabarozzi, A., Narducci, D., 2015. Formation of stable SiO-C submonolayers on hydrogenterminated silicon(111) under low-temperature conditions. Beilstein J. Nanotechnol. 6, 19-26. https://doi.org/10.3762/bjnano.6.3.

Korolkov, I.V., Mashentseva, A.A., Güven, O., Zdorovets, M.V., 2017. Modification of track-etched PET membranes by graft copolymerization of acrylic acid and N-vinylimidazole. Pet. Chem. 57, 1233-1241. https://doi.org/10.1134/ S0965544117130060.

Korolkov, I.V., Gorin, Y.G., Yeszhanov, A.B., Kozlovskiy, A.L., Zdorovets, M.V., 2018a Preparation of PET track-etched membranes for membrane distillation by photo-induced graft polymerization. Mater. Chem. Phys. 205, 55-63. https://doi.org/10 1016/j.matchemphys.2017.11.006.

Korolkov, I.V., Mashentseva, A.A., Güven, O., Gorin, Y.G., Zdorovets, M.V., 2018b. Protein fouling of modified microporous PET track-etched membranes. Radiat. Phys. Chem. 151, 141-148. https://doi.org/10.1016/j.radphyschem.2018.06.007.

Korolkov, I.V., Yeszhanov, A.B., Gorin, Y.G., Zdorovets, M.V., Khlebnikov, N.A., Serkov, K.V., 2018c. Hydrophobization of PET track-etched membranes for direct contact membrane distillation. Mater. Res. Express 5. https://doi.org/10.1088/2053-1591/ aacc39.

Korolkov, I.V., Yeszhanov, A.B., Zdorovets, M.V., Gorin, Y.G., Güven, O. Dosmagambetova, S.S., Khlebnikov, N.A., Serkov, K.V., Krasnopyorova, M.V., Milts, O.S., Zheltov, D.A., 2019. Modification of PET ion track membranes for membrane distillation of low-level liquid radioactive wastes and salt solutions. Separ. Purif. Technol. 227, 115694. https://doi.org/10.1016/j.seppur.2019.115694.

Kurakhmedov, A.E., Ivanov, I.A., Aleksandrenko, V.V., Kozlovskiy, A.L., Arkhangelsky, E., Zdorovets, M.V., 2017. Asymmetrical track-etched membranes prepared by doublesided irradiation on the DC-60 cyclotron. Petrol. chem. 52, 489-497. https://doi.org/ 10.1134/S0965544117060056.

Liu, H., Wang, J., 2013. Treatment of radioactive wastewater using direct contact membrane distillation. J. Hazard. Mater. 261, 307-315. https://doi.org/10.1016/J. JHAZMAT.2013.07.045.

McGaughey, A.L., Gustafson, R.D., Childress, A.E., 2017. Effect of long-term operation on membrane surface characteristics and performance in membrane distillation. J. Membr. Sci. 543, 143-150. https://doi.org/10.1016/j.memsci.2017.08.040.

Mulder, M., 1996. Transport in membranes. In: Basic Principles of Membrane Technology. Springer Netherlands, Dordrecht, pp. 210-279. https://doi.org/10.1007/978-94009-1766-8 5.

Naidu, G., Jeong, S., Johir, M.A.H., Fane, A.G., Kandasamy, J., Vigneswaran, S., 2017. Rubidium extraction from seawater brine by an integrated membrane distillationselective sorption system. Water Res. 123, 321-331. https://doi.org/10.1016/J. WATRES.2017.06.078.

Quist-Jensen, C.A., Macedonio, F., Horbez, D., Drioli, E., 2017. Reclamation of sodium sulfate from industrial wastewater by using membrane distillation and membrane crystallization. Desalination 401, 112-119. https://doi.org/10.1016/J.DESAL.2016. 05.007.

Ruiz-Aguirre, A., Andrés-Mañas, J.A., Fernández-Sevilla, J.M., Zaragoza, G., 2018 Experimental characterization and optimization of multi-channel spiral wound air 
gap membrane distillation modules for seawater desalination. Separ. Purif. Technol. 205, 212-222. https://doi.org/10.1016/J.SEPPUR.2018.05.044.

Shirazi, M.M.A., Kargari, A., Tabatabaei, M., 2014. Evaluation of commercial PTFE membranes in desalination by direct contact membrane distillation. Chem. Eng. Process. Process Intensif. 76, 16-25. https://doi.org/10.1016/J.CEP.2013.11.010.

Tijing, L.D., Woo, Y.C., Johir, M.A.H., Choi, J.-S., Shon, H.K., 2014. A novel dual-layer bicomponent electrospun nanofibrous membrane for desalination by direct contact membrane distillation. Chem. Eng. J. 256, 155-159. https://doi.org/10.1016/J.CEJ. 2014.06.076.

Wang, P., Chung, T.-S., 2015. Recent advances in membrane distillation processes: membrane development, configuration design and application exploring. J. Membr. Sci. 474, 39-56. https://doi.org/10.1016/j.memsci.2014.09.016.

Wang, P., Wang, M., Liu, F., Ding, S., Wang, X., Du, G., Liu, J., Apel, P., Kluth, P., Trautmann, C., Wang, Y., Wang, P., Wang, M., 2018. Ultrafast ion sieving using nanoporous polymeric membranes. Nat. Commun. 9. https://doi.org/10.1038/ s41467-018-02941-6.

Wang, Z., Yang, W., Sun, F., Zhang, P., He, Y., Wang, X., Luo, D., Ma, W., Sergio, G.C., 2019. Construction of a superhydrophobic coating using triethoxyvinylsilane-modified silica nanoparticles. Surf. Eng. 35, 418-425. https://doi.org/10.1080/ 02670844.2018.1446575.

Xu, J., Li, M., Zhao, Y., Lu, Q., 2007. Control over the hydrophobic behavior of polystyrene surface by annealing temperature based on capillary template wetting method. Colloids Surfaces A Physicochem. Eng. Asp. 302, 136-140. https://doi.org/ 10.1016/J.COLSURFA.2007.02.030.

Zakrzewska-Trznadel, G., 2013. Advances in membrane technologies for the treatment of liquid radioactive waste. Desalination 321, 119-130. https://doi.org/10.1016/j. desal.2013.02.022.

Zhao, D., Zuo, J., Lu, K.-J., Chung, T.-S., 2017. Fluorographite modified PVDF membranes for seawater desalination via direct contact membrane distillation. Desalination 413, 119-126. https://doi.org/10.1016/j.desal.2017.03.012. 